\title{
MEIO AMBIENTE E CONSUMO NO CONTEXTO DA SOCIEDADE DE RISCO: O IDEAL INDIVIDUALISTA FACE AO PRINCÍPIO DA SOLIDARIEDADE COMO MARCO JURÍDICO-CONSTITUCIONAL DO ESTADO “SOCIOAMBIENTAL" DE DIREITO
}

\section{Joana D'Arc Dias Martins*}

RESUMO: O artigo tem como ponto de partida a constatação de que se está diante uma sociedade de risco, e o consumo irracional contribui significativamente para ampliar o problema. Logo, uma nova ética na relação do homem com o meio ambiente precisa ser construída, sob pena de grave comprometimento da sobrevivência das espécies. Esta pesquisa apontará algumas alternativas que contribuam para a atenuação dessa crise, vistos como formas mais éticas de lidar com os bens ambientais e para a melhoria da qualidade de vida para as gerações atuais e futuras. Nesse estudo será utilizado o método dedutivo e a pesquisa bibliográfica.

PALAVRAS-CHAVES: Sociedade de risco; hiperconsumo; ética; economia circular; consumo colaborativo.

\section{ENVIRONMENT AND CONSUMPTION IN THE CONTEXT OF THE RISK}

\section{SOCIETY: THE INDIVIDUALIST IDEAL FACE THE SOLIDARITY PRINCIPLE \\ AS A LEGAL-CONSTITUTIONAL FRAMEWORK OF THE "SOCIO- ENVIRONMENTAL" STATE OF LAW.}

\begin{abstract}
The article's starting point is the realization that a risk society is facing, and irrational consumption contributes significantly to amplify the problem. Therefore, a new ethics in the relationship between man and the environment needs to be built, under penalty of serious compromise to the survival of species. This research will point out some alternatives that contribute to the mitigation of this crisis, seen as more ethical ways to deal with environmental goods and to improve the quality of life for current and future generations. In this study, the deductive method and bibliographic research will be used.
\end{abstract}

KEYWORDS: Risk society; hyperconsumption; ethic; circular economy; collaborative consumption.

\section{INTRODUÇÃO}

\footnotetext{
* Doutoranda e mestre em Direito pela Universidade de Marília - UNIMAR - Marília - São Paulo (Brasil). Especialista em Direito Público pela Ulbra, campus de Ji-Paraná/RO e em Direito Processual Civil pelo Instituto de Ensino Superior da Amazônia e Centro de Atualização e Estudos Jurídicos de São Paulo. Promotora de Justiça do Estado do Acre. E-mail: joanamartins.ac@gmail.com. Orcid: http://orcid.org/0000-0002-3666-6221
} 
O modelo de desenvolvimento adotado a partir da Revolução Industrial, pautado pela busca crescente de produção, atingiu níveis nunca antes imaginados, e como corolário, do consumo, que passou a ser incentivado, pois nada adiantaria produzir muito se não houvesse pessoas dispostas a consumir mais e rapidamente aqueles produtos que eram diariamente despejados nos mercados. Por consequência, juntamente com essa revolução, desenvolveu-se progressivamente uma sociedade de consumo dinâmica.

Porém, esse modelo equivocado de desenvolvimento, sem nenhuma preocupação com a finitude dos recursos naturais e baseado na equivocada premissa de que todo dano ao meio ambiente seria reversível, construiu uma sociedade que distribui riquezas com a mesma velocidade com que distribui riscos, cujos efeitos são intertemporais, afetando a qualidade de vida dos seres humanos no presente e a sobrevivência das futuras gerações e de todas as espécies que habitam o planeta.

Outrossim, indubitável que o processo de contínua degradação do planeta guarda estreita relação com o modo indiscriminado e sem maiores preocupações com que a humanidade vem transformando, consumindo e descartando os recursos naturais, o que denota que o homem tem relação direta com o comprometimento do equilíbrio ecológico do planeta e a intrínseca ligação existente entre a questão da proteção ambiental e o desenvolvimento econômico dos Estados.

Nesse contexto, o presente artigo trata da crescente preocupação com o impacto ambiental causado pelos atuais padrões de consumo e, também, da importância que o tema, diante do caráter transfronteiriço e intergeracional dos problemas ambientais, vem assumindo no cenário internacional.

Têm-se como ponto de partida a constatação de que se está diante de uma sociedade de risco, onde uma nova ética na relação do homem com o seu semelhante e o meio ambiente precisa ser urgentemente construída, sob pena de grave comprometimento da sobrevivência das espécies.

Malgrado as soluções para os problemas ambientais perpassar, obrigatoriamente, pelo envolvimento interdisciplinar dos diversos ramos do conhecimento, não remanesce dúvida de que o maior entrave advém da seara econômica, sendo essencial descobrir como conciliar economia e sustentabilidade, de modo que o crescimento econômico de uma nação reflita necessariamente na melhoria da qualidade de vida de seus habitantes, sobremodo no que concerne ao ususfruto dos direitos socioambientais. 
A ligação entre economia e meio ambiente é natural, e a natureza, como matériaprima, juntamente com o capital e o trabalho, formam o tripé da atividade econômica, sendo, portanto, dois ramos indissociáveis da ciência jurídica e que, em última análise, buscam a mesma finalidade: o aumento do bem-estar e a qualidade de vida individual e coletiva.

Como alternativa para a mitigação da crise ambiental e uma utilização mais ética e solidária dos bens ambientais, o artigo tratará suscintamente da economia circular e do consumo colaborativo, os quais podem incentivar o consumo responsável. Ademais, dado a importância do tema, tratar-se-á, também, da certificação sustentável, importante instrumento para auxiliar o consumidor na decisão de compra, indicando aqueles produtos e serviços que foram produzidos de forma ecologicamente corretas.

Por fim, a pesquisa se justifica principalmente pela atualidade e a relevância do tema. O método de abordagem é dedutivo e a técnica de pesquisa será bibliográfica e documental. $\mathrm{O}$ artigo está dividido em cinco tópicos que seguem os objetivos específicos do trabalho.

\section{O MEIO AMBIENTE NO CONTEXTO DA SOCIEDADE DE RISCO: ÉTICA E RESPONSABILIDADE}

A expressão sociedade de risco surge no âmbito da sociologia ao serem analisadas as características que marcam a sociedade da segunda modernidade. Essa sociedade, concebida no intuito de ampliar o conforto e a qualidade de vida dos seres humanos, paradoxalmente está marcada pela insegurança constante e pela produção de riscos globais que comprometem a própria existência no planeta. Segundo o sociólogo alemão Ulrick Beck (2002, p. 29), os desafios da sociedade de risco são os perigos produzidos pela civilização e que não podem ser delimitados socialmente, nem no tempo nem no espaço.

O Prêmio Nobel de química, Paul Crutzen, apelidou essa segunda modernidade como era do "Antropoceno" (SACHS, 2008, p. 67). Trata-se de uma época em que a Terra está dominada pelo ser humano - o "homo faber". Segundo Sachs (2008, p. 55), esse tempo é único em relação à tecnologia, aumento populacional e crescimento econômico. Tem-se, portanto, um mundo dinâmico e interconectado, mas, paradoxalmente, o Planeta está sendo empurrado para o colapso.

Portanto, a racionalidade do modelo de desenvolvimento atual, pautado no crescimento econômico sem limite, está comprometendo a dinâmica de todos os sistemas 
fundamentais para preservação da vida e transformando o Planeta sem respeitar os limites físicos da biosfera. O resultado desse estilo equivocado de vida é, nas palavras de Sachs (2008, p. 44), um planeta abarrotado, um modelo que privilegia o capital artificial em detrimento do natural, e que pensa que a natureza é descartável.

Na maior parte das culturas pré-modernas, mesmo nas grandes civilizações, os seres humanos se viam em perfeita sintonia com o meio ambiente, e suas vidas se encontravam entrelaçadas aos movimentos e às disposições da natureza, baseados na disponibilidade das fontes naturais do sustento, na prosperidade das plantações e animais, além dos próprios desastres naturais que eventualmente poderiam ocorrer. (GIDDENS, 1991, p. 66)

Nesse período, o único ambiente de risco era aquele ligado às vicissitudes de um mundo físico, relacionado às altas taxas de mortalidade infantil, baixa expectativa de vida, vulnerabilidade dos indivíduos a moléstias e pragas, receio dos efeitos devastadores de eventos naturais - inundações, tormentas, etc. -, atuação de exércitos invasores, saqueadores e piratas, que circundavam as aldeias. (GIDDENS, 1991, p. 108-110)

Portanto, conquanto a ausência de cuidados ambientais na era pré-moderna também se mostrasse recorrente, suas consequências eram detectadas sensorialmente, além de que, hodiernamente se encontrava relacionada à falta de higiene. Diferentemente, na civilização atual os riscos produzidos, na maioria das vezes, sequer são perceptíveis, porque estão camuflados, afetando os sistemas vitais sorrateiramente. Além disso, não decorrem de uma subprovisão de tecnologia higiênica, ao contrário, suas causas estão ligadas à superprodução industrial. (BECK, 2019, p. 26)

A sociedade atual, outrora acostumada com a previsibilidade das situações, convive agora com a insegurança constante de novas e inesperadas ameaças, cujas soluções são cobradas insistentemente de um Estado que não dá conta de saná-las.

Nesse novo rearranjo social, começam a tomar corpo ameaças produzidas até então pelo modelo econômico da sociedade industrial, baseado em um progressivo desequilíbrio proporcionado pelo crescimento e aperfeiçoamento das necessidades humanas, conjugados a um sistema que não se atentou ao necessário respeito à esgotabilidade dos recursos naturais, dando ensejo a uma verdadeira crise ambiental na qual a sociedade passa a conviver com risco permanente de desastres e catástrofes sobre os quais não tem mais controle.

Diante desse cenário, nem mesmo o desenvolvimento científico acumulado ao logo dos anos tem sido capaz de aferir o teor dos riscos gerados pela incessante produção de riqueza. 
O perigo passou a ser uma realidade muito vívida e pode estar em todo lugar. E isso tudo acontece sem que se possa avaliar adequadamente a potencialidade dessa ameaça. Os riscos socioecológicos contemporâneos são peculiares, na medida em que, sendo provenientes do próprio desenvolvimento tecnológico e econômico, e originários das engenharias nuclear, química, ambiental e genética, são de difícil identificação no tempo e no espaço, atingindo escala global. Além disso, são, muitas vezes, invisíveis, superando os sistemas de segurança. Exemplo típico é o caso da explosão do reator na usina nuclear de Chernobyl, na Ucrânia, na qual, inclusive, as previsões científicas falharam. (SEBASTIÃO, 2011, p. 178)

Agora o dano ambiental tem condições de projetar seus efeitos no tempo sem haver uma certeza e um controle de seu grau de periculosidade. É possível citar como exemplos os danos anônimos (impossibilidade de conhecimento atual), cumulativos e invisíveis, o efeito estufa, chuva ácida e muitos outros. Os referidos exemplos são provas incontestáveis da crise ambiental, bem como da necessidade de implantar formas alternativas de reparação do dano e de compensação ecológica.

Dentro desse novo marco da realidade os riscos são multicausais, imperceptíveis e de consequências imprevisíveis e imensuráveis. Tem caráter global e sinérgico, não respeitam fronteiras nem as diferenças sociais. Seus efeitos são intertemporais, afetando a qualidade de vida dos seres humanos no presente e a sobrevivência das futuras gerações e todas as espécies que habitam o planeta. (MONTERO, 2014, p. 48)

Ademais, toda essa proliferação das situações de risco acaba por vitimizar não só a geração presente, projetando-se, também, para as futuras gerações. No que concerne ao elemento tempo, Ayala (2003, p. 32) destaca que o sistema jurídico protetivo deve ser apreciado como um elemento fundamental “[...] nas opções e seleção das medidas de controle dos riscos, porque a qualidade global e o anonimato potencial expõem o desenvolvimento da vida a estados de insegurança, cujo momento e duração não podem ser cientificamente determinados com a certeza suficiente".

Diante de tal contexto, a capacidade para conciliar desenvolvimento econômico em longo prazo e equilíbrio ambiental está sendo objeto de um debate profundo em diversos âmbitos do conhecimento. Segundo Peralta Montero (2014, p. 43) “[...] a atual trajetória da atividade humana é insustentável em longo prazo; os próprios limites do meio ambiente acabarão frustrando as nossas aspirações globais de propriedade. Repensar essa forma de vida é sem dúvida um dos maiores desafios da sociedade atual". 
A verdade é que o homem, na busca incessante pelo crescimento econômico, esqueceu-se de integrar o elemento ecológico como parte do desenvolvimento. Logo, percebe-se que a problemática ambiental moderna é o resultado de uma crise da civilização. Nesse tocante, Enrique Leff (2006, p. 15) explica que: "Não é uma catástrofe ecológica nem um simples desequilíbrio da economia. É a própria desarticulação do mundo ao qual conduz a coisificação do ser e a superexploração da natureza; é a perda do sentimento da existência que gera pensamento racional em sua negação da autoridade".

De mais a mais, embora os riscos produzidos pela modernidade afetem de forma mais contudente as classes sociais menos assistidas, um novo componente surge nessa lógica distributiva, denominada de "efeito bumerangue", o que acaba por desconfigurar o esquema de classes, deixando todos em situação de vulnerabilidade, independentemente de suas posições econômicas. Ulrick Beck (2019, p. 27) aponta que "os riscos da modernização cedo ou tarde acabam alcançando aqueles que os produziram ou lucraram com eles". Revela-se, nesse ponto, o caráter supranacional dos riscos que emanam dos meios de produção da modernidade tardia. Os limites fronteiriços são sistematicamente rompidos, não só em sua pura acepção geográfica, mas sobremodo em seu aspecto geopolítico, com ameaças à legitimidade, à propriedade e ao lucro.

Nessa nova sociedade de risco, os processos de disputa já não se dão mais em relação ao acesso e à distribuição de bens, mas no poder de evitar ou distribuir os males provindos da própria modernização. Criou-se uma igualdade negativa em que os riscos ecológicos de grande consequência passam a ser democráticos e as pessoas tornam-se iguais, não mais pelos seus direitos ou benefícios que alcançam, mas pelos males ambientais que compartilham. (LENZI, 2006, p. 133-134)

Assim sendo, após anos de pressão sobre os bens ecológicos e de aplicação de um modelo econômico totalmente equivocado, baseado na crença cega advinda do benefício dos ganhos tecnológicos e científicos, depara-se com uma sociedade que fecundou em seu próprio berço perigos e riscos incalculáveis para a sua sobrevivência. Uma sociedade "que distribui riqueza" com a mesma velocidade com que "distribui riscos". (BECK, 2019, p. 25)

Outrossim, a natureza já não pode mais ser pensada sem a sociedade, e a sociedade já não pode ser pensada sem a natureza. As antigas teorias sociais dos séculos passados que pensavam a natureza como algo dado, destinado a se submeter, não podem mais ser aplicadas. (BECK, 2019, p. 89) 
Aqui reside um ponto fundamental, pois uma nova forma reflexiva de ver e entender o mundo precisam ser imposta. A formação desta "nova sociedade" exige uma inovadora modalidade de interpretar o mundo, em que todos os seres vivos são membros de comunidades ecológicas ligadas umas às outras, em uma rede de interdependência. (SCHONARDIE, 2004, p. 54)

A tomada de decisões pelo ser humano, no tocante à proteção do meio ambiente frente à sociedade de risco, deve ser necessariamente pautada pela moralidade, uma vez que as consequências da intervenção na natureza podem abarcar, não espantosamente, a sobrevivência da própria espécie humana. (FENSTERSEIFER, 2008, p. 58-59)

De resto, não há que se olvidar que no contexto de globalização dos riscos, "poucas pessoas, em qualquer lugar do mundo, podem continuar sem consciência do fato de que suas atividades locais são influenciadas, e às vezes até determinadas, por acontecimentos ou organismos distantes", de forma que uma decisão de consumir determinados produtos pode gerar severas implicações, que vão desde a sobrevivência de alguém do outro lado do mundo até a deflagração de um processo de deterioração ecológica com consequências para toda a humanidade. (GIDDENS, 2012, p. 91-92)

Enfim, diante da manifesta ameaça ecológica a que a atual sociedade se encontra submetida, mostra-se indispensável inserir a ética no debate da problemática ambiental. Desse modo, o discurso ético deve caminhar conjuntamente com o discurso ambiental visando permitir ao homem reorientar seu relacionamento com a natureza, de modo que o desenvolvimento seja duradouro e sustentável.

\section{A SOCIEDADE DE HIPERCONSUMO: A BUSCA DE EQUILIBRIO ENTRE O HOMEM E O AMBIENTE}

No contexto da sociedade de risco, um aspecto de suma importância a ser apurado envolve o papel do consumo na degradação dos bens ambientais e quais os caminhos a serem perseguidos visando à reversão desse processo. As evidências demonstram que a ação do homem sobre a natureza tem provocado uma crise sem precedentes, originada pelos equivocados padrões de desenvolvimento econômico. A forma e a intensidade de exploração ambiental, aliada ao excesso de consumo, ocasionam graves consequências e desequilíbrio a todo o ecossistema. 
Precipuamente a partir da Revolução Industrial, houve um incremento acelerado da produção, atingindo níveis nunca antes imaginados, e como seu corolário, do consumo, que passou a ser incentivado, pois nada adiantaria produzir muito se não houvesse pessoas dispostas a consumir mais e rapidamente, aqueles produtos que eram diariamente despejados nos mercados. Por conseguinte, juntamente com essa revolução, desenvolveu-se progressivamente uma sociedade de consumo dinâmica.

Sobre essa nova sociedade que se desenvolveu a partir da Revolução Industrial, os ensinamentos de Vieira e Reis (2016, p. 139):

O novo formato da produtividade trouxe um dinamismo para o mercado, uma vez que as produções eram realizadas em série e em grandes variedades e quantidades, o que despertou no indivíduo um enorme desejo pelo consumo. Com a industrialização em acelerado desenvolvimento e produção, a sociedade passou a ter acesso de forma facilitada aos bens de consumo.

O desenvolvimento industrial e a busca incessante pelo acúmulo de riqueza resultaram em um crescimento desenfreado da produtividade e do hiperconsumo. Os anseios capitalistas criaram na mente humana necessidades artificiais, fato que acabou por dar vazão à sociedade do desperdício, conforme bem analisado por Carlos Gabaglia Penna (2000, p. 34).

Todavia, foi a partir das décadas que sucederam o segundo pós-guerra, tendo os Estados Unidos como seu maior expoente, visto como modelo e referência positiva de desenvolvimento para os demais países, que esse estilo de vida consumista se massificou. À época, os Estados Unidos contavam com uma enorme capacidade industrial que necessitava ser mantida em funcionamento, o que não combinava com a utilização de produtos duráveis. O economista e analista de vendas americano, Victor Lebow, ao analisar a situação do país no período, e ao tratar sobre a necessidade de impulsionar sua economia, propôs uma nova tática social a ser imposta para o desdobramento econômico-social. Em seu artigo intitulado "Price Competition in 1955", publicado no Journal of Retailing, ele registra o espírito da época:

A nossa enorme economia produtiva exige que façamos do consumo nossa forma de vida, que tornemos a compra e uso de bens em rituais, que procuremos a nossa satisfação espiritual, a satisfação de nosso ego, no consumo. O status social, a aceitação social e o prestígio agora são medidos por nosso padrão de consumo. O próprio significado e importância de nossas vidas é hoje expressa em termos de consumo [...]. Precisamos que as coisas sejam consumidas, gastas, desgastadas, substituídas e descartadas em um ritmo cada vez maior. [...]. (LEBOW, 1995) 
A partir daí, inconscientemente as pessoas passaram a sofrer um processo de contínua manipulação e tornaram-se seres autômatos, tendo a mídia como uma das maiores responsáveis por influenciar o consumismo irracional. Esse método de desenvolvimento econômico foi aceito e rapidamente se difundiu.

O sociólogo francês Jean Baudrillard é um dos muitos críticos do papel desempenhado pela mídia como agente estimulador do estilo de vida consumista da sociedade atual. Para ele, a publicidade dos tempos atuais serve para ajudar o consumidor a racionalizar seu processo de compra, pouco importando se acredita nela ou não, desde que se estabeleça o interesse recíproco em preservar a relação entre ambos. Ainda, segundo o autor (2004, p. 169):

[...] nesta sociedade do consumo conquistou-se o direito de viver de forma perdulária, endividando-se num modelo semelhante ao feudalismo, em que e deve antecipadamente uma parte do seu trabalho ao senhor - exceto pelo fato de que o sujeito contemporâneo submete-se a ele voluntariamente.

No início do século XXI, o consumo que já vinha crescendo de forma desordenada nos séculos anteriores, tornou-se a base da sociedade e transformou-se em um estilo de vida, um ideal que deveria ser buscado.

Desenvolveu-se uma vontade crônica em adquirir bens, a paixão pelo novo e o desenvolvimento de um modo de vida centrado em valores materiais (LIPOVETSKY, 2007, p. 139-140). Passou a existir, por assim dizer, uma preocupação imediatista com a satisfação dos desejos. A felicidade passa a ser vista como a utopia materializada da abundância. É em nome dela que se desenvolve a sociedade hiperconsumista. A ideologia do capitalismo de consumo começa a ser representada na fé otimista da conquista da felicidade pela aquisição de bens materiais. (LIPOVETSKY, 2007, p. 335)

A relação desse homem perante o consumo é o que se pode denominar de “consumocentrismo" (CALGARO; PEREIRA, 2019, p. 406), caracterizada pela posição central que a aquisição de bens ocupa na vida das pessoas. O consumocentrismo está dirigido para o adestramento dos consumidores para adquirir e usufruir de bens e serviços que, na maioria das vezes, não necessitam. Esse comportamento leva a uma individualização cada vez maior das pessoas, cuja preocupação não está na sociedade, e sim nelas mesmas.

Quando o consumo é colocado nesse patamar, os problemas ambientais e sociais são simplesmente desconsiderados, pois interessa mais a nova moda a ser lançada e as questões 
mercadológicas. É a difusão do aparentar em detrimento do ser, onde as pessoas, sob o fascínio do consumo, se conjugam com o vazio e o espetáculo que essa sociedade consumocentrista oferece. Segundo os autores:

As pessoas se pautam no que a mídia e o marketing afirmam, configurandose e reconfigurando-se dentro dos ditames mercadológicos em uma estreita relação de adestramento. No que se refere aos discursos ambientais, esses também são alinhados à ideia consumocentrista, onde os apelos para a sustentabilidade passam pelo filtro do mercado, onde o consumidor é endereçado para o que importa ao mercado e não para as questões ambientais em uma verdadeira armadilha do sistema capitalista. (CALGARO; PEREIRA, 2019, p. 406)

Desse modo, a sociedade moderna "efêmera e descentralizada" (EAGLETON, 1998, p. 07), cuja característica marcante é o consumismo alienado, a avidez pela aquisição é quase que um movimento involuntário do homem, que não mais supre apenas suas vontades materiais com algo, mas preenche suas necessidades emocionais com bens.

Esse “consumo emocional” (LIPOVETSKY, 2007, p. 45) representa uma nova relação do indivíduo com as mercadorias, por mais paradoxal que possa parecer a subjetivação de uma material relação de consumo. É a civilização do desejo. "O materialismo da primeira sociedade de consumo passou de moda: assistimos à expansão do mercado da alma e de sua transformação, do equilíbrio e da autoestima, enquanto proliferam as farmácias da felicidade". (LIPOVETSKY, 2007, p. 15)

O sociólogo polonês Zygmunt Bauman (2001, p. 11) é um crítico a esse estílo de vida, que ele denomina de "modernidade líquida", onde nada foi feito para durar, construída sobre pilares frágeis da insegurança e do consumo. Para o autor, a sociedade atual, que denomina como sociedade do consumo, vive a "economia do engano", baseada na "[...] irracionalidade dos consumidores, e não em suas estimativas sóbrias e bem informadas; estimula emoções consumistas e não cultiva a razão". (BAUMAN, 2008, p. 64-65)

Ainda, segundo Zygmunt Bauman (2008, p. 60), o consumo é o valor mais característico da sociedade atual e seu valor supremo, em relação a qual todos os outros são instalados a justificar seu mérito, sendo o primado de uma vida feliz. Essa sociedade de consumidores talvez seja a única na História humana a prometer felicidade na vida terrena. Uma felicidade instantânea e perpétua, porém, paradoxalmente, baseada na própria insatisfação do consumidor, pois sem a contínua frustação dos desejos, e a permanente 
infelicidade que dela decorre, a demanda pelo consumo logo de esgotaria e a economia voltada para o consumidor ficaria sem combustível. (BAUMAN, 2008, p. 64)

Assim, não há que se olvidar que os padrões de consumo atual precisam ser imediatamente repensados, sob pena de inviabilizar a continuidade da vida no planeta. A ideia de mudar as formas de consumo vem ao encontro da possibilidade de desenvolver a economia, porém sem degradar o meio ambiente e ajudar a construir um ambiente socialmente justo e ético. Logo, importante que todos se conscientizem de que cabe a cada um a responsabilidade pelo futuro do planeta e para com o outro.

\section{CERTIFICADOS DE SUSTENTABILIDADE COMO INSTRUMENTO DE COMBATE À DELETÉRIA PRÁTICA DO GREENWASHING}

A demanda por produtos e serviços que respeitem o meio ambiente e a sociedade vem se intensificando no mundo social, principalmente diante do esgotamento do modelo de consumo subjacente ao capitalismo contemporâneo. Nesse diapasão, gradativamente os cidadãos têm buscado alternativas de consumo que tragam benefícios à comunidade, não só em curto, mas também em longo prazo. Consequentemente, mais e mais consumidores comparam produtos e serviços não somente em termos de preço e funcionalidade, mas também em virtude do impacto ambiental associado à produção, ao funcionamento e ao seu descarte. Não só as alternativas menos intrusivas são consideradas, como também os próprios objetivos do consumo são colocados em questão. Esses consumidores, mais cônscios do seu papel, dão preferência a empresas que atuam com responsabilidade ambiental, ainda que isso implique gastar mais para "consumir melhor".

À vista disso, as certificações de sustentabilidade, também conhecidos como "selos verdes" ou "eco-selos" foram criadas justamente no intuito de auxiliar o consumidor na decisão de compra, visto que a empresa certificada como tal, pressupõe que possui preocupações sustentáveis e que auxilia na melhoria das condições ambientais do planeta. São empresas que já se deram conta de que a cidadania empresarial é um bom negócio, além de ser uma estratégia de posicionamento perante o mercado, configurando um importante diferencial competitivo para seus produtos e marcas. Portanto, ao buscarem a certificação ambiental, elas visam demonstrar que incorporam princípios de sustentabilidade em seus negócios e fazem investimentos tendentes a reduzir as externalidades negativas provenientes 
do exercício de sua atividade econômica.

Atualmente as empresas brasileiras lideram a busca por selo global de sustentabilidade. Em janeiro de 2020 havia no país dez companhias de capital aberto na fila para obter a certificação do "Sistema B", programa com mais de 200 métricas que avalia a sustentabilidade. Contando com as pequenas e médias, são 5.800 empresas que iniciaram o processo de medição. Presente em mais de 70 países, o sistema é um conjunto de métricas que posicionam empresas em uma escala de 0 a 200 (sendo 80 o mínimo necessário). O programa é aplicado em cerca de 150 setores econômicos. Segundo Marcel Fukayama, presidente da certificadora no país, "O Brasil tem o maior pipeline [fluxo] de empresas nesse processo no mundo. São 5.800 que iniciaram o processo de medição, o que coloca o Brasil no protagonismo de uma economia mais inclusiva e sustentável”. (SOPRANA, 2020)

A certificação sustentável também é uma tendência na União Europeia já há algum tempo. No dia 18 de junho de 2020, o Parlamento Europeu aprovou novas regras para determinar se uma atividade econômica é ambientalmente sustentável, e como corolário, criou o "selo verde", o qual deverá ser atribuído a empresas e projetos com o escopo de guiar investimentos públicos na União Europeia. Ademais, outro objetivo é que qualquer investidor, pessoa física ou jurídica, saiba se seu dinheiro está sendo aplicado em atividades que colaboram para a preservação do ambiente ou a prejudicam. (PINTO, 2020)

Segundo restou estabelecido, para que a atividade econômica possa ser contemplada com o selo de ecologicamente correta, dentre os cinco objetivos ambientais previstos pela legislação europeia, a atividade deve contribuir para pelo menos um deles sem, entretanto, prejudicar significativamente nenhum dos outros. Os objetivos que precisam ser atendidos são i) redução das mudanças climáticas ou adaptação a elas; ii) uso sustentável e proteção dos recursos hídricos e marinhos; iii) transição para a economia circular (incluindo prevenção de resíduos); iv) prevenção e controle da poluição e v) proteção e restauração da biodiversidade e dos ecossistemas.

Ademais, a legislação vai permitir que a Comissão Europeia defina que atividades são prejudiciais ao ambiente. "A eliminação de investimentos nessas atividades é tão

\footnotetext{
${ }^{1}$ Selo concedido a quem utiliza a iniciativa privada para gerar benefícios sociais e ambientais - uma espécie de setor dois e meio. O selo nasceu há oito anos nos Estados Unidos e já foi exportado para outros 38 países. No Brasil há pouco mais de um ano, o Sistema B, organização responsável pela certificação, já conta com 41 empresas nacionais, em sua maioria pequenas e médias. Os aprovados são obrigados a incluir no estatuto o compromisso com a geração de benefícios sociais e ambientais para toda a comunidade -garantindo que, em um momento de crise, as boas intenções não ficarão relegadas ao discurso.
} 
importante quanto o incentivo às consideradas sustentáveis", afirmou o eurodeputado pela Holanda, Bas Eickhout, do Partido Verde, após a aprovação da lei. Embora a lei entre em vigor assim que publicada, os critérios específicos para o primeiro objetivo devem estar prontos no final de 2020, e os outros quatros, dentre eles a classificação de atividades ambientalmente danosas, devem ser feita até dezembro de 2021. (PINTO, 2020)

Por outro lado, com a entrada em vigor das novas regras, todos os produtos financeiros que afirmam ser sustentáveis, doravante terão que provar essa condição seguindo critérios rigorosos (PINTO, 2020). Outrossim, um dos objetivos primordiais da nova lei é coibir a deletéria prática do greenwashing, também conhecida como "lavagem verde", consitente em fornecer informações falsas sobre produtos ou atividades fazendo com que alguma coisa aparente um enganoso aspecto ecológico. Ou seja, a falsa informação disseminada por uma instituição cujo objetivo é apresentar uma imagem pública de responsabilidade ambiental que não corresponde à realidade.

Essa "maquiagem verde", disseminada sobremodo através de agressivas estratégias de marketing, geralmente conseguem ludibriar o consumidor, às vezes pouco informado ou ávido por consumir produtos ecologicamente corretos ocasionando graves consequências, para o consumidor e, principalmente, para o meio ambiente.

Nesse contexto, os certificados verdes se mostram deveras importantes e um grande passo rumo à sustentabilidade, haja vista apresentarem grande potencial para inibir a atuação de empresas sem nenhum comprometimento com a causa ambiental, mas que de forma fraudulenta vinculam a ideia de sustentabilidade ambiental à publicidade de produtos e serviços que nada possuem de sustentáveis. Esses empreendimentos usam a preservação ambiental em manobras publicitárias apenas no intuito de atrair o consumidor, ou eventualmente usufruírem de benefícios fiscais voltados às empresas ecologicamente responsáveis.

Como é consabido, as empresas verdadeiramente engajadas com as causas ambientais e que atuam em observância ao uso equilibrado e racional dos recursos naturais, acabam sendo prejudicadas, pois as concorrentes, ao fazerem uso desse estelionato midiático, atraem consumidores para a aquisição de seus produtos, que, por razões óbvias, podem vendê-los a preços mais acessíveis. Por outro lado, a prática do greenwashing, ao vincular uma falsa imagem de compromisso ambiental a determinados produtos e serviços, elevam ainda mais o consumo de produtos degradantes e o aumento da pressão exercida sobre os bens ambientais. 
Fato incontroverso é que o próprio consumidor, mais consciente do seu papel e do poder que detém, já compreendeu que as mudanças de paradigmas perpassam por suas escolhas na aquisição de bens e serviços, dando preferência para aqueles produzidos de forma ecologicamente correta. Destarte, o empresário que deseja fortalecer sua marca e apresentar seus produtos e serviços como atrativos ao mercado, mais do que nunca precisa demonstrar à sociedade que tem genuinas preocupações socioambientais.

Conforme os ensinamentos de Gerd Winter (2013, p. 65), no mundo social, a ecoproporcionalidade vem se difundindo no âmbito do chamado consumo ambiental. Assim, mais e mais consumidores comparam produtos e serviços não somente em termos de preço e funcionalidade, mas também em termos do impacto ambiental associado à produção, ao funcionamento e ao seu descarte.

Perfilhando esse mesmo entendimento, as ponderações de Lipovetsky (2007, p. 344):

[...] optam por produtos éticos, recusam a identificação com as marcas, compram alimentos biodinâmicos, interrogam-se sobre o impacto ambiental dos produtos: comportamentos que demonstram uma preocupação em ser antes ator "responsável" que "vítima" passiva do mercado. Aceitando pagar mais caro por produtos que preservam o meio ambiente, informando-se sobre as condições sociais nas quais os artigos são fabricados, esforçando-se para minimizar seu consumo de energia (casa ecológica, transporte), esses consumidores de um novo gênero envolvem-se pessoalmente em seu modo de consumo.

Por conseguinte, não há que se olvidar da forte influência que a população consumerista exerce no mercado e do poder que de causar prejuízos consideráveis a um empresário socialmente irresponsável. Nesse sentido, Robert Henry Srour (2003, p. 52) observa que:

A sociedade civil reúne condições para organizar-se e retaliar as empresas
socialmente irresponsáveis ou inidôneas. Os clientes, em particular, ao
exercitar seu direito de escolha e migrar simplesmente para os concorrentes,
dispõem de uma indiscutível capacidade de dissuasão, uma espécie de
arsenal nuclear. A cidadania organizada pode levar os dirigentes
empresariais a agir de forma responsável em detrimento, até, de suas
convicções íntimas.

Todavia, a despeito da inequívoca importância das certificações ambientais para um relacionamento mais ético com o meio ambiente, esse instrumento somente atingirá a eficácia pretendida se o Estado e, sobremodo o próprio consumidor, não se apegarem apenas aos rótulos ou propagandas que ressaltem essa qualidade e buscarem informações 
verdadeiramente confiáveis acerca das atividades da empresa que, potencialmente, possa se enquadrar nessa categoria, sob pena da sustentabilidade se resumir a um rótulo.

Em vista disso, imprescindível que a população busque educar-se ambientalmente para que possa bem exercer a cidadania ecológica e assuma de vez seu protagonismo como defensora das causas ambientais, sendo que o Conselho Nacional de Autorregulamentação Publicitária (CONAR) e o Estado, através do seu sistema jurídico, devem atuar em harmonia no intuito de garantir que apenas empresas sérias, realmente comprometidas e transparentes, permaneçam no mercado.

\section{NOVOS PARADIGMAS DE RACIONALIZAÇÃO E CONSERVAÇÃO DOS RECURSOS COMO INSTRUMENTO PARA O DESENVOLVIMENTO SUSTENTÁVEL: ECONOMIA CIRCULAR E CONSUMO COLABORATIVO}

O ciclo do consumo é essencialmente composto por produção, armazenamento, consumo e descarte. Nada obstante, no consumismo esse ciclo se repete com maior intensidade, sobretudo quando estimulado pela ideologia da obsolescência programada, que fomenta a produção de bens seletivamente frágeis, semiobsoletos ou sazonais. Some-se a isso ávidos consumidores que encontram na aquisição de bens um meio para validar quem são e satisfazer necessidades emocionais, cujo impacto ambiental passa ao largo de suas preocupações. As necessidades imediatas, embaladas pelas eficientes campanhas de marketing, prejudicam a clareza de raciocínio, e seu instinto de satisfação pessoal - mais imediatos e viscerais - falam mais alto.

Como consequência, a cada dia observa-se o aumento expressivo do consumo de produtos fabricados com materiais altamente poluentes, cuja decomposição, após o descarte, é muito longa e com representativo prejuízo para o meio ambiente. Diante desse contexto, e considerando que do ponto de vista do planeta, não existe "jogar lixo fora", porque simplesmente não existe "o fora", é preciso discutir e implementar a economia circular e o consumo colaborativo visando o desenvolvimento sustentável.

O conceito de cadeia produtiva, definido como um conjunto de atividades que contemplam, desde a produção até o consumo final de um produto, retrata, em parte, o atual modelo linear de produção, caracterizado por um sistema de produzir, utilizar e descartar. Analisando as recentes preocupações em produzir de forma sustentável, evidencia-se que o 
modelo linear se mostra ultrapassado, podendo ser apontado, ainda, como a causa imediata de impactos ambientais, muitas vezes irreversíveis aos ecossistemas. Nesse contexto, surge como proposta o modelo de economia circular, que visa justamente reverter esse processo e reincorporar os resíduos ao sistema de produção, acarretando alterações positivas nos índices de desenvolvimento social, econômico e ambiental.

Com essa mudança de paradigmas de um sistema futuro, a economia circular propõe um novo modelo de sociedade, com a criação de novos contornos para a produção, circulação e consumo, otimizando materiais, energias, resíduos e buscando a eficiência do uso desses recursos. O objetivo é converter os resíduos cada vez mais em matérias primas.

Nessas tintas, a economia circular trata de um modelo que exige mudanças de paradigmas, seja nas empresas, por conta de redesenho das cadeias produtivas e dos modelos de negócio, seja na sociedade como um todo, ou, sobremodo, por parte dos governos, para viabilizar a operacionalização desse modelo em longo prazo, ou seja, todos os atores devem participar desse círculo, cada um desenvolvendo o seu papel.

A Agenda de Desenvolvimento Sustentável da ONU - Organização das Nações Unidas, inclusive, tem o tema "Consumo e produção responsáveis" como um de seus Objetivos de Desenvolvimento Sustentável (ODS), agenda de recomendações para orientar políticas em defesa dos direitos humanos e do meio ambiente para 2030, bem como a Estratégia Europa 2020, que pretende gerar um crescimento inteligente, sustentável e integrado de maneira global. Atualmente, uma das principais estratégias é impulsionar o crescimento e gerar emprego, com suporte do Parlamento e do Conselho Europeu. Interessante observar o envolvimento das seguintes áreas: Produção e consumo; gestão de resíduos; matérias primas secundárias e competitividade e inovação.

Outro importante instrumento que pode contribuir na implementação de um desenvolvimento sustentável é o consumo colaborativo, voltado para a redução das pegadas ecológicas do homem no planeta.

O consumo colaborativo vem sendo difundido nos últimos tempos como uma prática mais racional, menos egoística e degradante, além de muito mais sustentável, visto que o meio ambiente é poupado em função do reaproveitamento de bens. Tal associação se deve ao fato de essa forma de consumir implicar, na maioria das vezes, utilização coletiva de um bem ou serviço ou o repasse e reutilização de produtos de segunda mão, o que amplia o tempo de vida dos bens. “Assim, o desenvolvimento das atividades de consumo colaborativo, apesar de 
participar da atual cultura de mercado, se expressa como uma das tendências que equilibram ou ainda contrariam o consumismo". (PAIXÃO; SOUSA, 2015, p. 173)

Por conseguinte, na atualidade, é comum ver pessoas compartilhando espaços de suas residências ou meios de transporte, como veículos e bicicletas, ou tendo acesso a roupas, brinquedos e livros apenas pelo tempo que estes objetos lhes são úteis. Também é usual presenciar trocas de serviços entre indivíduos de acordo com a habilidade e competência de cada um.

Destarte, o consumo colaborativo emerge com a missão de alterar os padrões atuais de consumo, focando no alcance de níveis de consumo mais sustentáveis, envolvendo a construção de relações entre diversos setores sociais, como produtores, comerciantes e consumidores. Ou seja, é uma alternativa para alcançar o desenvolvimento sustentável, visto suplantar o hiperconsumo e criar sistemas inovadores fundamentados no compartilhamento.

Dessa forma, ao aumentar a eficiência do uso de bens e serviços, o consumo colaborativo reduz o desperdício, incentiva o desenvolvimento de produtos melhores e absorve o excedente de produção e consumo, contribuindo de forma significativa para a higidez ambiental. Consequentemente, esse modo de consumir permite às pessoas o acesso aos produtos e serviços por um período temporário, entretanto suficiente para suprir as suas necessidades, sem, contudo, gerar uma capacidade ociosa de tais bens. (BOTSMAN; ROGERS, 2011, p. 38).

Logo, a melhoria da qualidade de vida, a sustentabilidade, o consumo responsável, a preocupação ambiental e social, a redução de gastos e do próprio consumo são ideias ou termos constituintes do conceito de consumo colaborativo e com ele guardam estreita relação.

Ao dissertar sobre o tema e sobre as vantagens relacionadas com a adoção do consumo colaborativo, Barros e Patriota (2017, p. 7) afirmam:

[...] o processo de mudança do consumo tradicional para o "consumo colaborativo" marcaria a transição de uma prática "vergonhosa" para outra "virtuosa". Assim, o "consumerismo" ocuparia o lugar do "consumismo", ou o "hiperconsumo" seria substituído pelo "autocontrole", por "negócios mais justos" e "democráticos" e por relações que "não são obcecadas pelo material".

Por conseguinte, é possível afirmar que tanto a economia circular quanto o consumo colaborativo estão diretamente relacionados à preocupação moderna com o bem comum e com o meio ambiente e têm como finalidade precípua incentivar o consumo ético, responsável 
e solidária, além da melhoria da qualidade de vida para as gerações atuais e futuras.

\section{CONSIDERAÇÕES FINAIS}

Conforme restou demonstrado no presente artigo, as intervenções praticadas pelo homem no meio ambiente vêm ampliando progressivamente as possibilidades de riscos ambientais que podem comprometer gravemente todas as formas de vida na terra. Por outro lado, as questões que envolvem sacrifícios em prol de benefícios futuros são extremamente dificultadas. É um mundo onde o imediatismo e o individualismo imperam.

Nesse contexto, a sociedade contemporânea caminha rumo a uma civilização fundamentada no risco, na qual ônus e benesses são socializados numa mesma trama mundial que a todos envolve. Na marcha em direção a um novo modelo de convivência, a humanidade segue ameaçando a si mesma, tendo em vista que a sociedade distribui, a um só tempo, riquezas e riscos.

É preciso abandonar o atual modelo de desenvolvimento, pautado exclusivamente no crescimento econômico e buscar outro que respeite a natureza e utilize de modo racional os recursos naturais. A sustentabilidade não pode ser vista como mero modismo ou utopia inalcançável, mas sim uma necessidade para a sobrevivência do planeta Terra.

Como corolário, vital encontrar novos modos de produzir e consumir, fazendo escolhas éticas que promovam o desenvolvimento sustentável, de modo a não comprometer as opções das futuras gerações. Afinal, foi justamente a necessidade de extrema prudência uma das principais marcas de nascença desse novo valor que é a sustentabilidade.

Nesse processo, o consumo consciente tem papel preponderante. Escolhas cotidianas do consumidor, seja na forma de consumir, seja optando por empresas com responsabilidade socioambiental, pode ajudar a construir uma sociedade mais justa, solidária e sustentável.

Por fim, fundamental questionar os valores impostos pela sociedade de consumo e buscar novos paradigmas para a vida em sociedade. A consciência acerca do consumo responsável constitui um importante passo rumo à sustentabilidade e depende da colaboração de todos, o que somente será possível com atitudes verdadeiramente éticas que supere a coisificação do meio ambiente.

\section{REFERÊNCIAS BIBLIOGRÁFICAS}


AYALA, Patryck de Araújo. A proteção jurídica das futuras gerações na sociedade do risco global: direito ao futuro na ordem constitucional brasileira. In: LEITE, José Rubens Morato; FERREIRA, Heline Sivini (orgs). Estado de direto ambiental: perspectivas. Rio de Janeiro. Forense Universitária, 2003.

BARROS, Ana Cirne Paes de; PATRIOTA, Karla Regina. Macena Pereira. Consumo colaborativo: perspectivas, olhares e abordagens para um conceito em construção. Signos do Consumo, São Paulo, v. 9, n. 2, p. 4-15, jul./dez. 2017.

BAUDRILLARD, Jean. O Sistema dos objetos. São Paulo: Perspectiva. 2004.

BAUMAN, Zygmunt. A vida para o consumo: A transformação das pessoas em mercadoria. Rio de Janeiro: Jorge Zahar, 2008.

BAUMAN, Zygmunt. Modernidade líquida. Rio de Janeiro: Jorge Zahar, 2001.

BECK, Ulrich. La sociedade del risgo global. Madrid: Siglo Veintiuno, 2002.

BECK, Ulrich. Sociedade de risco: Rumo a uma outra modernidade. Trad.

Sebastião Nascimento. São Paulo: Editora 34, 2019.

BIANCHI, Patrícia Nunes Lima. Meio ambiente: certificações ambientais e comércio internacional. Curitiba: Juruá, 2008.

BOTSMAN, Rachel; ROGERS, Roo. O que é meu é seu: como o consumo colaborativo vai mudar o nosso mundo. Porto Alegre: Bookman, 2011.

COMISSÃO MUNDIAL SOBRE MEIO AMBIENTE E DESENVOLVIMENTO, ONU, 1987.

Relatório Brundtland. Disponível em: http://ambiente.wordpress.com/2011/03/22/relatriobrundtland-a-verso-original. Acesso em: 16 de jun. 2020.

EAGLETON, Terry. As ilusões do pós-modernismo. São Paulo: Editora Jorge, 1998.

FENSTERSEIFER, Tiago. Direitos fundamentais e proteção do ambiente: a dimensão ecológica da dignidade humana no marco jurídico-constitucional do Estado Socioambiental de Direito. Porto Alegre: Livraria do Advogado, 2008.

GIDDENS, Anthony. As conseqüências da modernidade. Tradução: Raul Fiker. $6^{\text {a }}$ reimp. São Paulo: Unesp, 1991.

GIDDENS, Anthony. A vida em uma sociedade pós-tradicional. In: BECK, Ulrich; GIDDENS, Anthony; LASH, Scott. Modernização reflexiva: política tradição e estética na ordem social moderna. São Paulo: Unesp, 2012.

JONAS, Hans. O princípio da responsabilidade: Ensaio de uma ética para a civilização tecnológica. Rio de Janeiro: Contraponto, 2006.

LEBOW, Victor. Price competition in 1955. Journal of retailing, v. 31, n. 1, p. 5-10, 1955. Disponível em: http://ablemesh.co.uk/PDFs/journal-of-retailing1955.pdf. Acesso: 19 jun. 2020. 
LEFF, Enrique. Racionalidade ambiental: a reapropriação social da natureza. Tradução de Luís Carlos Cabral. Rio de Janeiro: Civilização Brasileira, 2006.

LENZI, Cristiano Luis. Sociologia ambiental: risco e sustentabilidade na modernidade. Bauru: Edusc, 2006.

LIPOVETSKY, Gilles: A felicidade paradoxal: Ensaio sobre a sociedade de hiperconsumo.

Trad. de Maria Lucia Machado. São Paulo: Companhia das Letras, 2007.

MONTERO, Carlos Eduardo Peralta. Tributação ambiental: reflexões sobre a introdução da variável ambiental no sistema tributário. São Paulo: Saraiva, 2014.

OST, François. A natureza à margem da lei: A ecologia à prova do direito. Lisboa: Instituto Piaget, 1997

PAIXÃO, Claudia Resem; SOUSA, Richard Perassi Luiz de. Consumo colaborativo: tendência de construção de conhecimento e negócios no mercado digital de produtos usados. Perspectivas em Gestão \& Conhecimento, João Pessoa, v. 5, n. 2, p. 170-185, jul./dez. 2015.

PENNA, Carlos Gabaglia. O estado do planeta: sociedade de consumo e degradação ambiental. Rio de Janeiro: Bertrand Brasil, 2000.

PEREIRA, Agostinho Oli Koppe; CALGARO, Cleide. O constitucionalismo latino-americano e o consumocentrismo: as consequências socioambientais na sociedade moderna. Revista Jurídica LusoBrasileira, ano 05 (2019) n.6. Lisboa, p. 391-423, 2019. Disponível em: http://www.cidp.pt/revistas/rjlb/2019/6/2019_06_0391_0423.pdf. Acesso: 02 jun. 2020.

PINTO, Ana Estela de Sousa. Europa cria 'selo verde para priorizar investimento em atividades sustentáveis. Folha de São Paulo. 18 jun. 2020. Disponível em:

https://www1.folha.uol.com.br/mercado/2020/06/europa-cria-selo-verde-para-priorizar-investimentoem-atividades-sustentaveis.shtml. Acesso: 1 de jul. 2020.

SACHS, Jeffrey. Economía para um planeta abarrotado. Buenos Aires: Debate, 2008.

SCHONARDIE, Elenise Felzke. Direito penal ambiental na sociedade do risco e imputação objetiva. Revista Ibero-Americana de Ciências Penais, Porto Alegre, ano 5, n. 56, 2004.

SEBASTIÃO, Simone Martins. Tributo ambiental: extrafiscalidade e função promocional do direito. Curitiba: Juruá, 2011.

SOPRANA, Paula. Empresas brasileiras lideram busca por selo global de sustentabilidade. Folha de São Paulo. 21 jan. 2020. Disponível em: https://www1.folha.uol.com.br/mercado/2020/01/empresasbrasileiras-lideram-busca-por-selo-global-de-sustentabilidade.shtml. Acesso. 1 de jul. 2020.

VIEIRA, Gabriela Castro; REIS, Émilien Vilas Boas. A sociedade de risco desenfreado e os impactos ambientais. Revista Argumentum, Marília, São Paulo, v. 17, p. 139-140, 2016.

WINTER, Gerd Winter. Proporcionalidade Eco-Lógica: um Princípio Jurídico Emergente para a Natureza?. Veredas do Direito: Direito Ambiental e Desenvolvimento Sustentável, Belo Horizonte, v. 10, n. 20, abr. 2014, p. 55-78. Disponível em:

http://revista.domhelder.edu.br/index.php/veredas/article/view/422. Acesso: 14 Jul. 2020. 
